\title{
Study on Diffusion Bonding of Metals*
}

\author{
By Ichiro Kawakatsu** and Seiji Kitayama***
}

\begin{abstract}
Metallographical phenomena among many factors which control weldability on diffusion bonding has been investigated. Combinations of the base metals were classed into three types; the solid solution type, two-phase type and intermetallic compound type. Diffusion bonding was carried in hydrogen atmosphere using several bonding pairs such as $\mathrm{Cu}-\mathrm{Ni}, \mathrm{Cu}-\mathrm{Ag}, \mathrm{Cu}-\mathrm{Al}$, and $\mathrm{Fe}-\mathrm{Al}$.

The influence of the bonding temperature and time on the bonding strength was investigated and the microstructure at the interface was observed.

The minimum bonding temperature exists in the neighborhood of the softening temperature of one of two base metals. The increasing process of the initial bonding strength is considered as a transient phenomenon from recovery to recrystallization with stored energy and depends on the bonding temperature and time, satisfying Arrhenius' equation. The bonding strength depends on the softening of base metals and alloying at the interface above the recrystallization temperature of the base metals. In the case of the solid solution type, the bonding strength increases with the rise of the bonding temperature and time. In the case of $\mathrm{Cu}-\mathrm{Ag}$ joints, the effect of the bonding condition is not very large, but the bonding strength increases rapidly after 30 min heating at $700^{\circ} \mathrm{C}$. In the case of the intermetallic compound type, the alloy layer increases in thickness and the bonding strength deteriorates in $\mathrm{Fe}-\mathrm{Al}$ joints rapidly above the recrystallization temperature. The bonding interface tends to disappear with time above the recrystallization temperature of both base metals of the solid solution type, but it is retained as an interfacial boundary in the case of the two-phase type and the intermetallic compound type.
\end{abstract}

(Received November 19, 1976)

\section{Introduction}

Recently, advances in aircraft and aerospace engineering are remarkable and the kind of new materials is now on the increase.

Diffusion bonding is one of new bonding methods being applied to new materials. This method is used to obtain the joints which have minimum deformation and deteriorations in the mechanical property of base metals by bonding below the solidus temperature under suitable pressure.

Generally, in the solid state bonding, weldability is controlled by the following three factors $^{(1)(2)}$.

(1) The bonding condition such as bonding temperature, bonding time, bonding pressure, surface roughness, atmosphere, etc.

* This paper was originally published in Japanese in J. Japan Inst. Metals, 40 (1976), 96.

** College of Science \& Engineering, Aoyama Gakuin University, Tokyo 157, Japan.

*** Graduate School, Aoyama Gakuin University, Tokyo 157, Japan.
(2) Physical and chemical properties of base metals. These are the mechanical property, crystal structure, atomic radius, recrystallization temperature, surface energy and work function due to metals.

(3) Metallurgical properties, that is, mutual solubility of dissimilar metal combination and formation of intermetallic compound, such as the change in chemical composition.

In the case of cold pressure bonding which is carried at low temperature under high pressure for a short time, weldability is subjected to the bonding pressure and physical and chemical properties of metals.

Diffusion bonding which takes slight deformation by heating for a long time at high temperature is affected by oxidation, surface contamination and other inclusions. Further, in the case of joints between dissimilar metals, a diffusion layer is formed at the bonded interface. Therefore, metallurgical structure is a very important factor, with the bonding time and temperature and the surface condition.

On the other hand, in the study of bonding between dissimilar metals or sticking phe-

1977 Vol. 18 
nomena in metals, many papers have been published on metal adhesion or metal transfer in the field of wear ${ }^{(3)(4)}$. Recently, Iwata has reported on the relation between weldability and the physical property of base metals ${ }^{(5)}$, and Hashimoto on the mechanism of bonding ${ }^{(6)}$. But most of the reports have been concerned with pressure bonding. In the case of diffusion bonding, a bonding mechanism is proposed by King and Owczarski in connection with titanium bonding ${ }^{(7)}$.

As metallurgical problems as to joints between dissimilar metals, formation of a brittle intermetallic compound at the interface makes it difficult to produce good joints and the mutual solubility of each base metal is said to be needed $^{(8)}$. However, much remains unclarified in the mechanism of diffusion bonding and the relation between bonding strength and metallurgical changes on the interface.

In this paper, the metallographical phenomena and the bonding mechanism on diffusion bonding are investigated experimentally. Namely, combinations of the base metals were classed into three types; the solid solution type, two-phase type and intermetallic compound type. The effects of bonding temperature and time on the weldability have been investigated for the three types.

\section{Experimental Procedure}

\section{Specimens}

The materials used in this investigation were mild steel (SPCC1), phosphorus deoxidized copper (DCuPl), pure aluminum (99.99\%), pure nickel $(99.6 \%)$, and pure silver. They were cold rolled metals $(1 / 2 \mathrm{H})$ and $1.5 \mathrm{~mm}$ in thickness. Specimens were cut out from the sheet to have a rectangular form of about $12 \times 40 \mathrm{~mm}$. Mild steel and copper were pickled in aqua regia and other acids. After being degreased, these specimens were dryed in the desicator.

\section{Combinations of metals}

When each pair which was bonded with dissimilar metals was heated below the solidus temperature, the microstructure near the inter- face was classed into three types; (i) simple solid solution, (ii) two phases coexisting near the interface, and (iii) intermetallic compound formed at the interface. The bonding strength is considered to be affected by the metallurgical changes in the interface. Therefore, $\mathrm{Cu}-\mathrm{Ni}$, $\mathrm{Ag}-\mathrm{Cu}, \mathrm{Al}-\mathrm{Cu}$, and $\mathrm{Al}-\mathrm{Fe}$ were selected as bonding pairs. In the case of $\mathrm{Al}-\mathrm{Cu}$, copper has solid solubility in aluminum, while in the case of $\mathrm{Al}-\mathrm{Fe}$, iron has a very low solubility in aluminum.

\section{Experimental apparatus and bonding pro- cedure}

After the bonding surfaces were brushed up by wire brush, they were mounted on the holder of the lap joint type, $5 \mathrm{~mm}$ in length, which was made from mild steel and heated in the furnace at the prescribed temperatures for various times. The bonding pressure can be controlled by the fastening degree of the holder. That is, the pairs of $\mathrm{Ni}-\mathrm{Cu}, \mathrm{Ag}-\mathrm{Cu}, \mathrm{Al}-\mathrm{Cu}$ and $\mathrm{Al}-\mathrm{Fe}$ were clamped under pressures of about 3.5 , $3.5,2.0$ and $2.0 \mathrm{~kg} / \mathrm{mm}^{2}$, respectively. The bonding pairs were heated in a horizontal furnace into which hydrogen gas was flowed at a rate of $4 \sim 5 \ell / \mathrm{min}$ to protect the oxidation of the bonding surface. The specimen and its holder are schematically shown in Fig. 1.
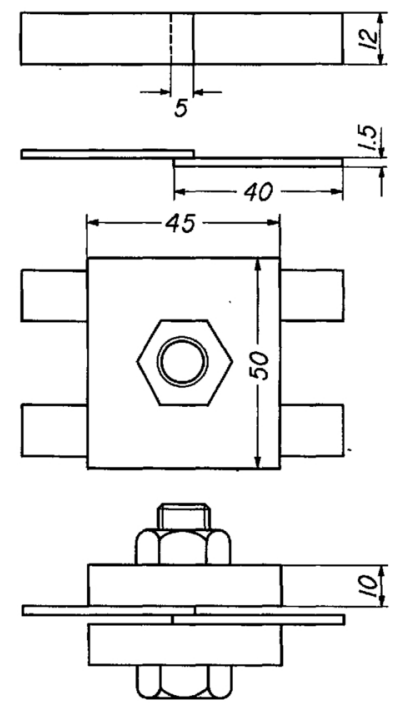

Fig. 1 Schematic drawing of the specimen and its holder. 


\section{Results}

\section{Influence of the bonding temperature and time on bonding strength}

After bonding, the bonding strength of lap joints has been calculated from the shear load for rupturing at a $1 \mathrm{~mm} / \mathrm{min}$ drawing rate. In this work the bonding strength used is above $0.5 \mathrm{~kg} / \mathrm{mm}^{2}$ and the minimum bonding temperature is the temperature for a bonding time of $10 \sim 15 \mathrm{~min}$.

The relation between bonding temperature and bonding strength for $\mathrm{Cu}-\mathrm{Ni}$ joints of the solid solution type for various bonding times is shown in Fig. 2. The minimum bonding temperature was $450^{\circ} \mathrm{C}$. The bonding strength increased with the rise of temperature until $600^{\circ} \mathrm{C}$ for each bonding time, but it decreased from 650 to $750^{\circ} \mathrm{C}$. This decrease in bonding strength is considered as the recrystallization of nickel which decreases the tensile strength and increases the elongation, and consequently deformation of the base metal on the copper side becomes remarkable. Above $750^{\circ} \mathrm{C}$, the bonding strength increases gradually. Compared with the fractured surfaces, bonded joints fracture on the copper side below $600^{\circ} \mathrm{C}$, but $700^{\circ} \mathrm{C}$ the joints fracture in the bonding interface. It is considered that mechanical property is improved by mutual diffusion between copper and nickel in the bonded interface in the copper side. In the relation between bonding strength and bonding time,

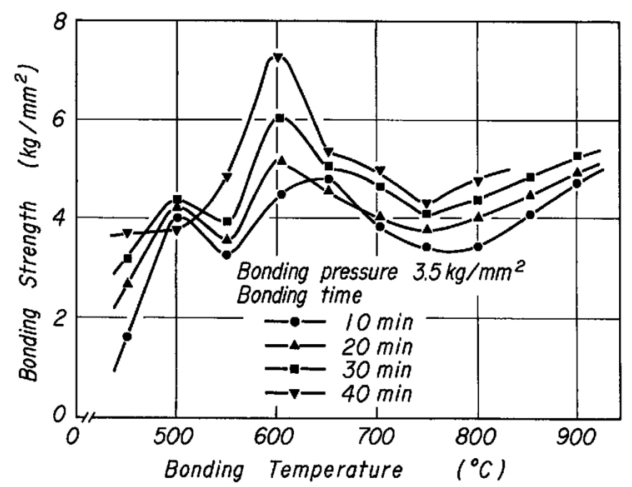

Fig. 2 Relation between bonding temperature and bonding strength as a function of time for $\mathrm{Cu}-\mathrm{Ni}$ joint.

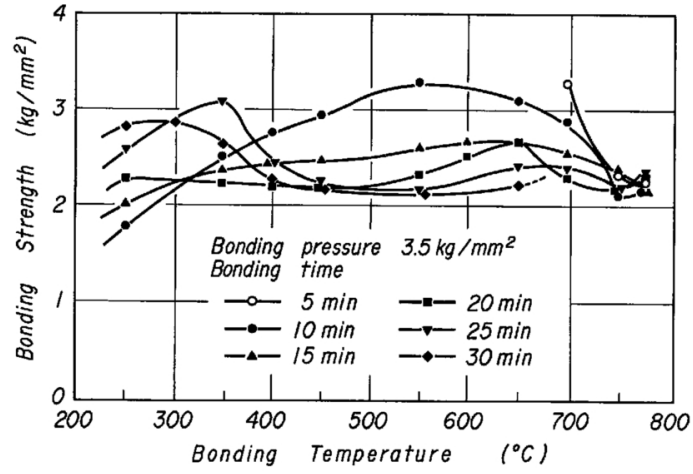

Fig. 3 Relation between bonding temperature and bonding strength as a function of time for $\mathrm{Cu}-\mathrm{Ag}$ joints.

the bonding strength tends to increase with bonding time. But at $550^{\circ} \mathrm{C}$ and $650 \sim 750^{\circ} \mathrm{C}$, such a tendency was less pronounced. It seems that the increase of the true bonded area is reduced, because the softening of copper and nickel base metals becomes constant at those temperatures. In the case of a $\mathrm{Cu}-\mathrm{Ag}$ joint which is the two-phase type having mutual solubility in some degree, the relation between bonding strength and bonding temperature for various bonding times is shown in Fig. 3 . The dotted line indicates the fracture of base metals. The minimum bonding temperature is about $250^{\circ} \mathrm{C}$. In the case when the bonding time was for $10 \mathrm{~min}$ at $550^{\circ} \mathrm{C}$ and for 25 or $30 \mathrm{~min}$ at $300 \sim 350^{\circ} \mathrm{C}$, the bonding strength was $3.0 \sim$ $3.2 \mathrm{~kg} / \mathrm{mm}^{2}$. Above these temperatures, the bonding strength decreases and the influence of bonding temperature is not very large. On the other hand, the bonding strength increases in the vicinity of $250^{\circ} \mathrm{C}$ with bonding time. For a long bonding time at $350^{\circ} \mathrm{C}$, the bonding strength decreases, whereas above $400^{\circ} \mathrm{C}$ the bonding strength decreases with bonding time. Above $700^{\circ} \mathrm{C}$ for $30 \mathrm{~min}$, the bonding strength increased rapidly and fracture occurred on base metal side, and not in the bonded zone.

Figures 4 and 5 show the relation between bonding strength and bonding temperature for $\mathrm{Cu}-\mathrm{Al}$ joints and $\mathrm{Fe}-\mathrm{Al}$ joints of the intermetallic compound type as a function of time. Metal transfer of aluminum is observed on the surfaces of copper and iron at $400^{\circ} \mathrm{C}$, but bonding does not occur by heating for 6 ) $\sim 80$ 


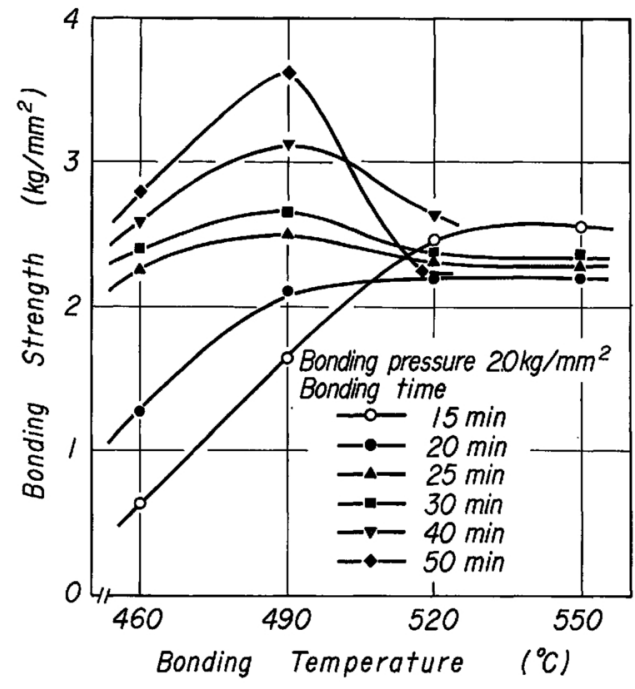

Fig. 4 Relation between bonding temperature and bonding strength as a function of time for $\mathrm{Cu}-\mathrm{Al}$ joints.

min. In the case of $\mathrm{Cu}-\mathrm{Al}$ joints, the minimum bonding temperature is $460^{\circ} \mathrm{C}$. In the relation between bonding strength and bonding temperature, bonding can easily occur above $520^{\circ} \mathrm{C}$ for $10 \sim 20 \mathrm{~min}$, but these joints form an intermetallic compound layer and most of the fracture occurs in this layer. As for the bonding time, the bonding strength increases with bonding time at 460 and $490^{\circ} \mathrm{C}$ when the intermetallic compound is formed slowly. In the case of $\mathrm{Fe}-\mathrm{Al}$ joints, the minimum bonding temperature is $520^{\circ} \mathrm{C}$. The joint strength increases with the rise of bonding temperature until $580^{\circ} \mathrm{C}$. But it decreases with the formation of the intermetallic compound as with the case of $\mathrm{Cu}-\mathrm{Al}$ joints above $580^{\circ} \mathrm{C}$, and deteriorates rapidly in the case of more than $20 \mathrm{~min}$ of bonding. The effect of bonding time can hardly

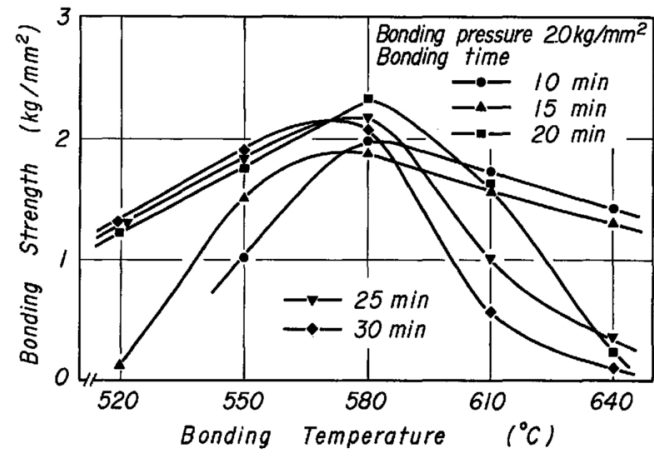

Fig. 5 Relation between bonding temperature and bonding strength as a function of time for $\mathrm{Fe}-\mathrm{Al}$ joints.

be observed even at temperatures below $580^{\circ} \mathrm{C}$.

\section{Observation of the bonding interface}

For specimen preparation, the bonding surface was brushed off by wire brush to a surface roughness of about $\mathrm{Hmax} 20 \sim 30 \mu$, after bonding the bonded interface was became very smooth, $5 \sim 8 \mu$ in roughness, compared with the original surface. Photograph 1 shows the bonding interface of $\mathrm{Cu}-\mathrm{Ni}$ joints of the solid solution type. There is a tendency to be corroded by etchant in the interface of joints between dissimilar metals ${ }^{(9)}$ containing various defects because of the differences in lattice structure and atomic radii and electrochemical property. So this pair was etched to such an extent that the bonded interface would remain. Photograph 1(a) shows a microstructure bonded at $700^{\circ} \mathrm{C}$ for $10 \mathrm{~min}$. Below $700^{\circ} \mathrm{C}$, the joints showed such a line of the bonded interface as in the case of cold pressure bonding, even if it had high strength. Photograph 1 (b) shows a microstructure bonded at $700^{\circ} \mathrm{C}$ for $30 \mathrm{~min}$.
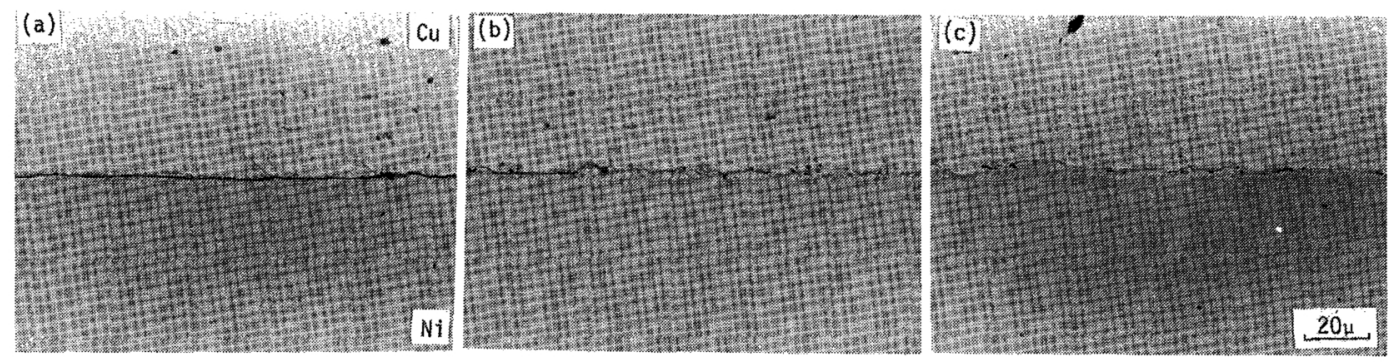

Photo. 1 Microstructures of cross sections of the $\mathrm{Cu}-\mathrm{Ni}$ bonded interface.

(a) and (b) bonded at $700^{\circ} \mathrm{C}$ for 10 and $30 \mathrm{~min}$, (c) bonded at $900^{\circ} \mathrm{C} \mathrm{for} 10 \mathrm{~min}$. 
It seems that the disappearance of the bonding interface begins partially. Photograph 1(c) shows a microstructure bonded at $900^{\circ} \mathrm{C}$ for $10 \mathrm{~min}$. The bonding interface observed in (a) and (b) disappeared for the most part. The interface energy decreased on the diffused layer, and defects and voids were absorbed into the base metal. In the microstructure of the base metal on the copper side, marked grain growth was observed above $750^{\circ} \mathrm{C}$. Photograph 2(a) and (b) are the microstructures at $550^{\circ} \mathrm{C}$ for $10 \mathrm{~min}$ and $30 \mathrm{~min}$, respectively. In Photo. 2(a) the bonding interface can be observed as in Photo. 1(a). In Photo. 2(b) is shown the diffusion layer, $2 \sim 4 \mu$ in thickness, which was etched in the grain boundary on the silver side. The location of the bonded interface was confirmed by means of microstructure observation. Photograph 2(c) and (d) are those at $775^{\circ} \mathrm{C}$ for $10 \mathrm{~min}$ and $30 \mathrm{~min}$, respectively.
Compared with these structures with the values of bonding strength, (b) and (c) showed the same bonding strength and fracture occurred in the bonding interface. In the case of (d), the diffusion layer observed in (b) and (c) was penetrated into the grain boundary of silver and its structure a mixture of diffused copper and silver base metal near the bonded interface. And fracture occurred on the silver side of the base metal. In the microstructures of the base metals, remarkable grain growth was observed. Photograph 3 shows the microstructures of $\mathrm{Cu}-\mathrm{Al}$ joints and $\mathrm{Fe}-\mathrm{Al}$ joints which are both the intermetallic compound type. Photograph 3(a) and (b) are those of $\mathrm{Cu}-\mathrm{Al}$ joints at 460 and $550^{\circ} \mathrm{C}$ for $30 \mathrm{~min}$, respectively. In (a) the intermetallic compound about $2 \sim 3 \mu$ in thickness is observed at the bonded interface, but in (b) the intermetallic compound about $10 \sim 15 \mu$ in thickness is seen over the entire region.
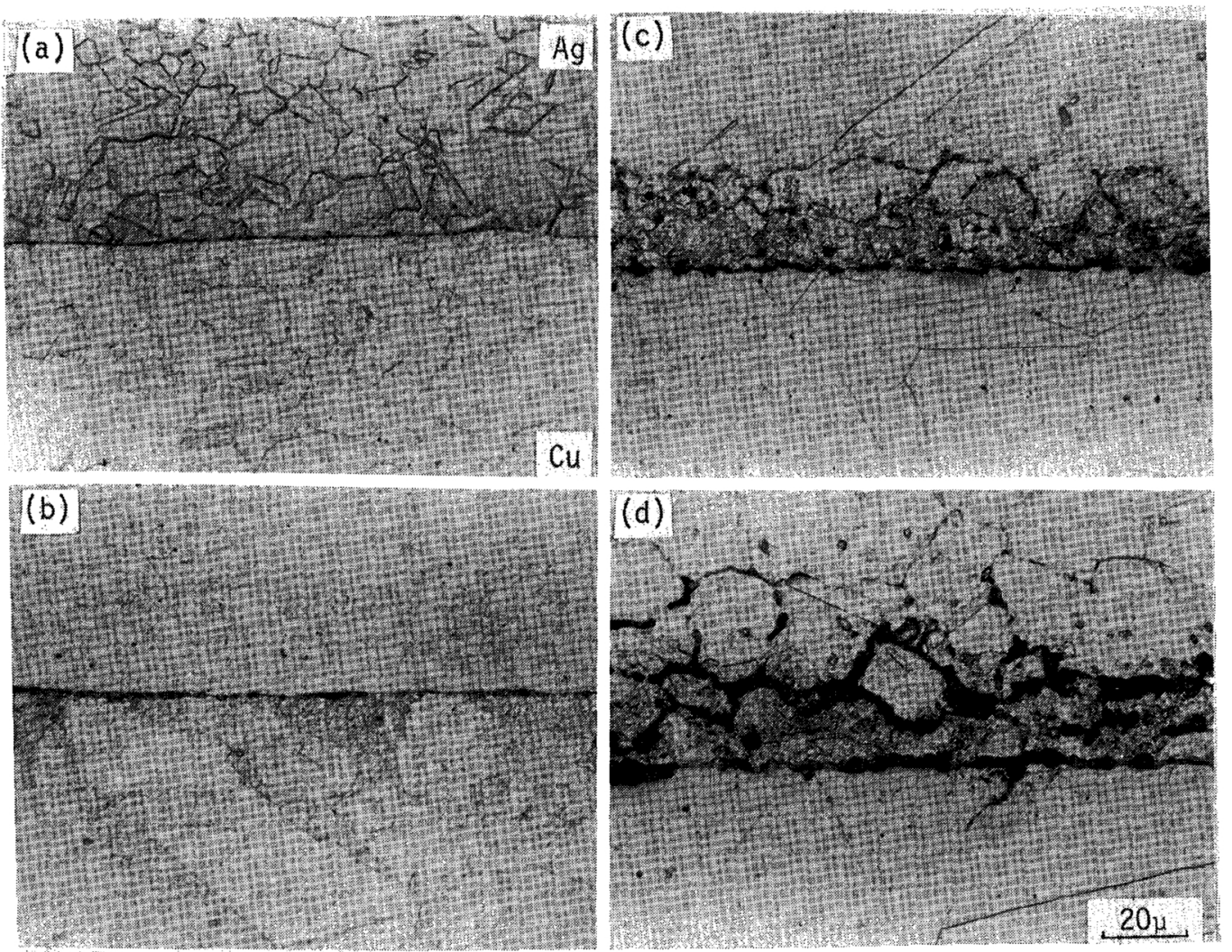

Photo. 2 Microstructures of cross sections of the $\mathrm{Cu}-\mathrm{Ag}$ bonded interface.

(a) and (b) bonded at $550^{\circ} \mathrm{C}$ for 10 and $30 \mathrm{~min}$, (c) and (d) bonded at $775^{\circ} \mathrm{C}$ for 10 and 30 min. 

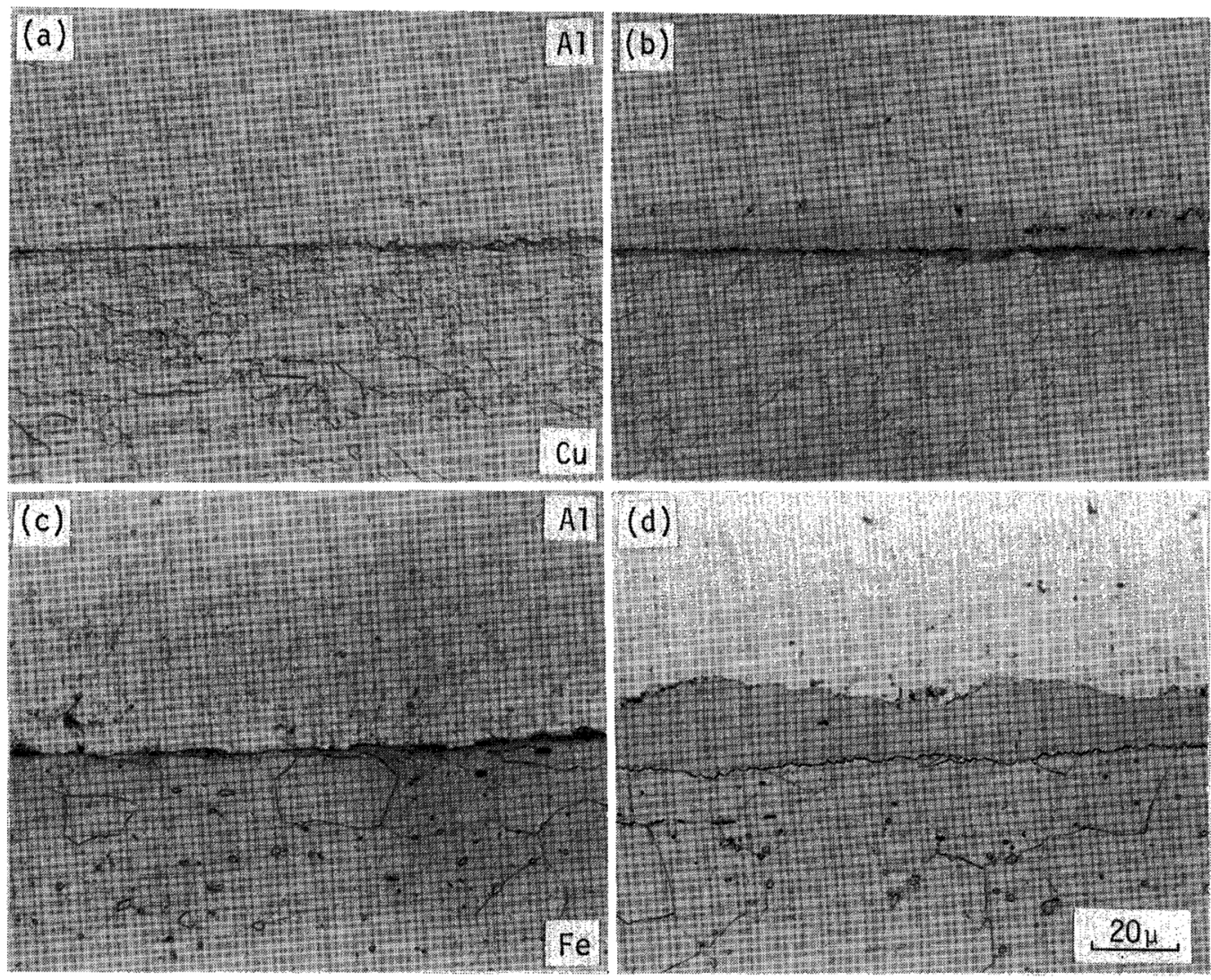

Photo. 3 Microstructures of cross sections of the $\mathrm{Cu}-\mathrm{Al}$ and $\mathrm{Fe}-\mathrm{Al}$ bonded interfaces.

(a) and (b) are $\mathrm{Cu}-\mathrm{Al}$ joints bonded at 460 and $550^{\circ} \mathrm{C}$ for $30 \mathrm{~min}$.

(c) and (d) are $\mathrm{Fe}-\mathrm{Al}$ joints bonded at 520 and $640^{\circ} \mathrm{C}$ for $30 \mathrm{~min}$.

Photograph 3(c) and (d) are the microstructures for $\mathrm{Fe}-\mathrm{Al}$ joints at 520 and $640^{\circ} \mathrm{C}$ for $30 \mathrm{~min}$, respectively. In (c) some voids are present, but no intermetallic compound is seen in the bonded interface. In the case of (d) which is higher in bonding temperature and longer in bonding time, the intermetallic compound about 10 20 $\mu$ in thickness can be observed in the bonded interface.

\section{E.P.M.A. analysis of the bonded interface}

Line analysis was performed on the cross sections of bonded interface for $30 \mathrm{~min}$ by means of E.P.M.A. The relative intensity was revised using Ref. (10).

Figure 6 shows a distribution of the characteristic $\mathrm{X}$-rays of $\mathrm{CuK} \alpha$ and $\mathrm{NiK} \alpha$ for $\mathrm{Cu}-\mathrm{Ni}$ joint bonded at $900^{\circ} \mathrm{C}$. The diffusion layer was about $13 \mu$ wide on the copper side and about

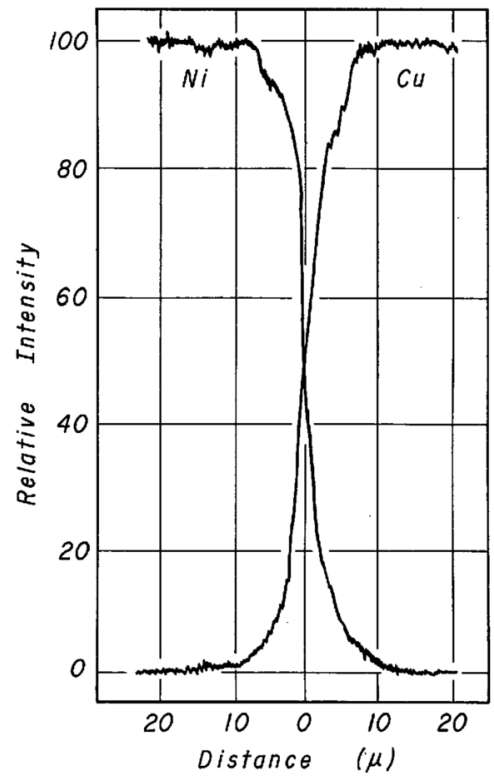

Fig. 6 Distribution of the $\mathrm{CuK} \alpha$ intensities at the interface of $\mathrm{Cu}-\mathrm{Ni}$ joints for $30 \mathrm{~min}$ at $900^{\circ} \mathrm{C}$. 
$10 \mu$ wide on the nickel side, and the copper side was more corrosive than the interface next to nickel. Although it has been well known that this pair forms Kirkendall voids in the interface, this was probably due to the fact that there was no Kirkendall effect and many defects formed by bonding still remained at the interface without being absorbed in the base metal. Figure 7 shows a distribution of the characteristic X-rays of $\mathrm{CuK} \alpha$ and $\mathrm{AgK} \alpha$ for $\mathrm{Cu}-\mathrm{Ag}$ joint bonded at $775^{\circ} \mathrm{C}$ for $30 \mathrm{~min}$. The copper concentration in silver was higher than that of silver in copper, and the diffusion layer was about $10 \mu$ wide on the copper side and about $40 \mu$ wide on the silver side. In the silver solid solution there was observed a copper-rich zone. This zone turned out to be black by etching in the microstructure of Photo. 2(d) and this zone corresponds well with the peak of the characteristic X-rays of $\mathrm{CuK} \alpha$. Though it was difficult to decide from this relative intensity, the zone was presumed to be the copper solid solution in consideration of the constitution diagram. Figure 8 shows a distribution of the characteristic X-rays of $\mathrm{CuK} \alpha$ and $\mathrm{AlK} \alpha$ for $\mathrm{Cu}-\mathrm{Al}$ joint and $\mathrm{FeK} \alpha$ and $\mathrm{AlK} \alpha$ for $\mathrm{Fe}-\mathrm{Al}$ joint. Figure 8 (a) is the microstructure at $550^{\circ} \mathrm{C}$ for $30 \mathrm{~min}$. The concentrations of copper

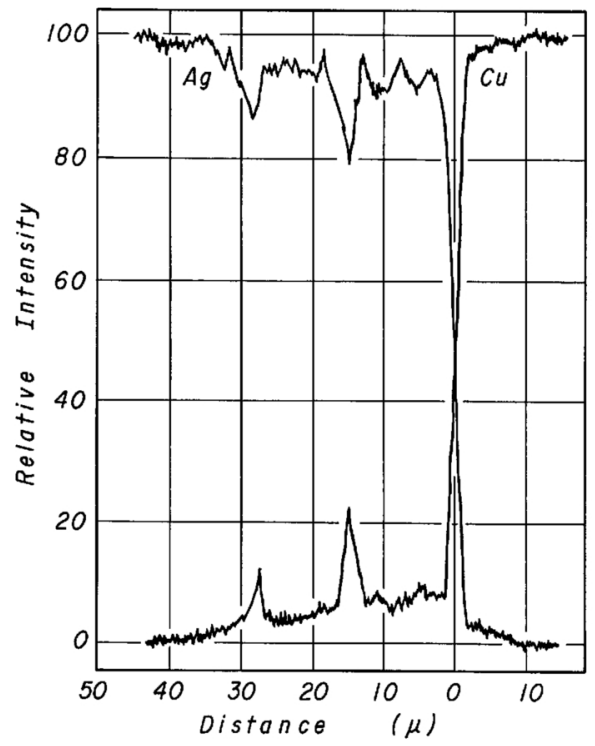

Fig. 7 Distribution of the $\operatorname{CuK} \alpha$ and $\operatorname{AgK} \alpha$ intensities at the interface of $\mathrm{Cu}-\mathrm{Ag}$ joints for $30 \mathrm{~min}$ at $775^{\circ} \mathrm{C}$.
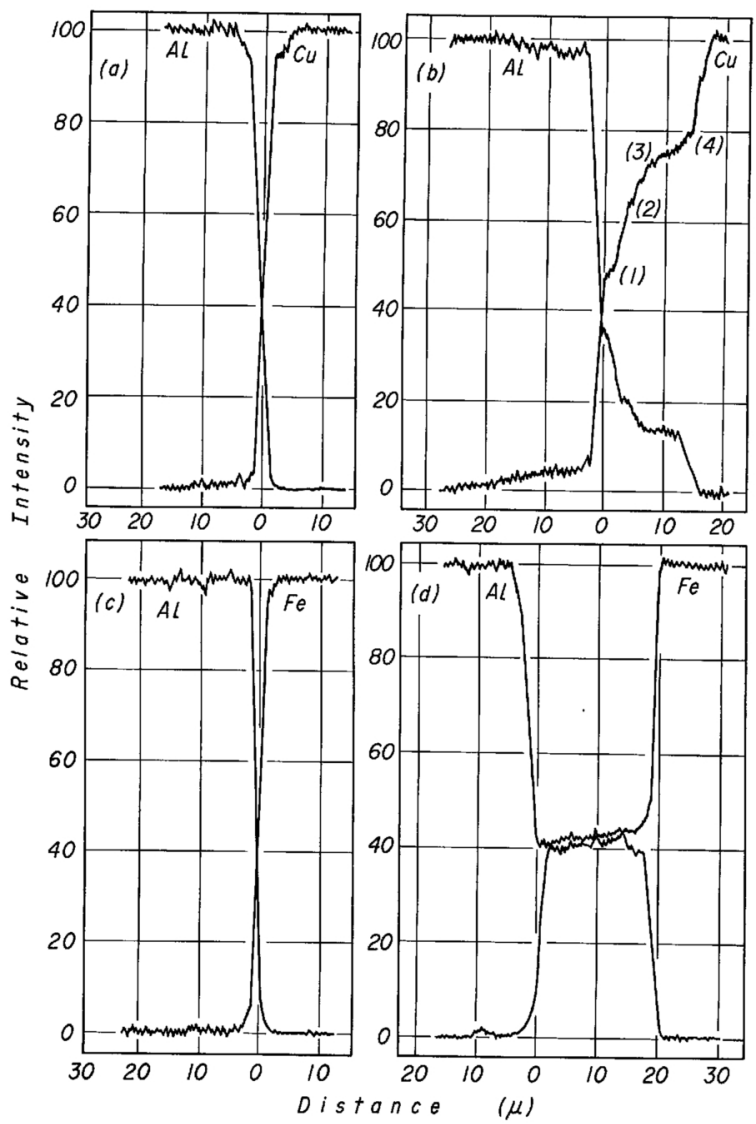

Fig. 8 Distribution of the $\mathrm{CuK} \alpha$ and $\mathrm{AlK} \alpha$ intensities at the interface of $\mathrm{Cu}-\mathrm{Al}$ joints and the $\mathrm{FeK} \alpha$ and $\mathrm{AlK} \alpha$ intensities at the interface of $\mathrm{Fe}-\mathrm{Al}$ joints. (a) and (b) are $\mathrm{Cu}-\mathrm{Al}$ joints bonded at 460 and $550^{\circ} \mathrm{C}$ for $30 \mathrm{~min}$. (c) and (d) are $\mathrm{Fe}-\mathrm{Al}$ joints bonded at 520 and $640^{\circ} \mathrm{C}$ for $30 \mathrm{~min}$.

and aluminum were about $4 \%$ on the aluminum side and about $6 \%$ on the copper side. The diffusion layer was about $4 \mu$ wide on the aluminum side and $3 \sim 4 \mu$ wide on the copper side. Figure $8(\mathrm{~b})$ is the one at $550^{\circ} \mathrm{C}$ for $30 \mathrm{~min}$. In this bonding condition, three layer intermetallic compounds in the bonded interface were observed in the microstructure in Photo. 3(d). The distributions of the characteristic $\mathrm{X}$-rays of $\mathrm{CuK} \alpha$ and $\mathrm{AlK} \alpha$ in the compounds were divided into the following regions by comparing with the constitution diagram of each phase: Regions (1) and (2) in Fig. 8(b) were $\mathrm{CuAl}_{2}$ and $\mathrm{CuAl}$, respectively; region (3) was probably $\mathrm{Cu}_{12} \mathrm{Al}_{9}$ though it was not observed in the microstructure of Photo. 3(d); 
and (4) was $\mathrm{Cu}_{3} \mathrm{Al}_{2}$. On the other hand, Fig. 8(c) and (d) are the microstructures bonded at 520 and $640^{\circ} \mathrm{C}$, respectively. In Fig. 8(c) almost no diffusion of iron and aluminum takes place because of their small solubility. In Fig. 8(d) there is observed the intermetallic compound $\mathrm{FeAl}_{3}$ about $20 \mu$ wide at the bonded interface.

\section{Discussion}

Generally, the bonding process of joints between dissimilar metals is considered as follows. Figure 9 shows a schematic representation of these processes. In Fig. 9(a) and (2) represent the first stage, where bonding occurs partially and the bonded area increases gradually by plastic deformation on the surface of base metals, and alloying take places slightly with mutual diffusion at the bonded section. In Fig. 9(3) and (4) express the second stage, where defects such as voids, oxide films and other inclusions which remain in the bonded interface diminish in the base metal and forms a diffusion layer near the bonded interface. The ultimate bonding strength seems to depend strongly on two factors. One is the increasing action of bonding strength due to the alloying in the bonded section or the increase of the true contact area at the interface. The other is the decreasing action of bonding strength due to the softening of base metal or the embrittlement due to the formation of an intermetallic compound in the process of each stage. Then the weldability of various joints on each stage is considered as follows. Figure 10 shows the

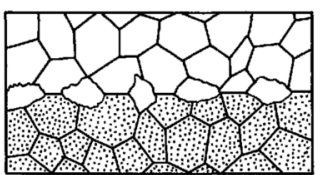

(1)

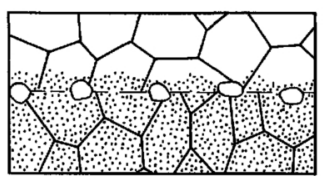

(3)

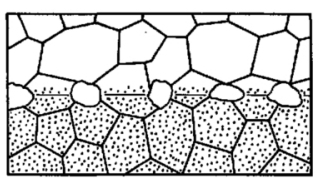

(2)

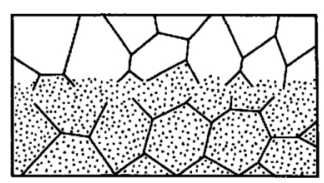

(4)
Fig. 9 Schematic representation of the diffusion bonding process.

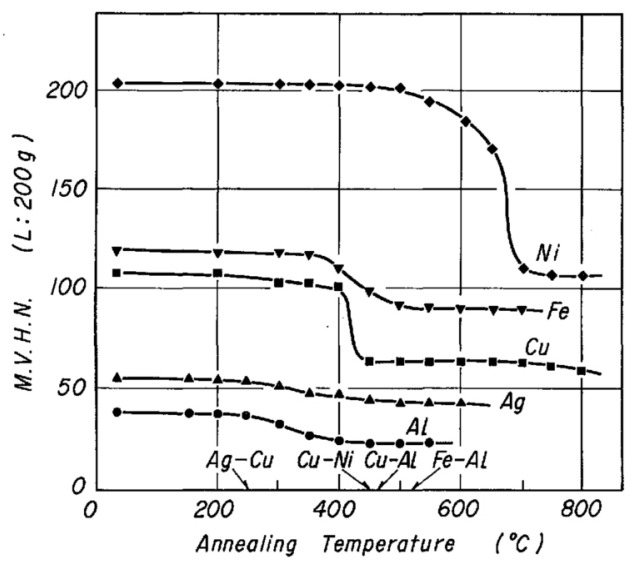

Fig. 10 Relation between annealing temperature and micro-Vickers hardness of specimens and minimum bonding temperature for various joints.

relation between annealing temperature and micro-Vickers hardness of specimens and expresses the minimum bonding temperature of various joints. In the case of $\mathrm{Cu}-\mathrm{Ni}$ and $\mathrm{Cu}-\mathrm{Ag}$ joints, bonding occurred at a lower softening temperature of each combination metal. It can be explained as follows. Since the yield stress of base metals is decreased by heating, the deformation of asperities in the interface has become easier and the true contact area has increased in the bonding surface. In the case of $\mathrm{Cu}-\mathrm{Al}$ and $\mathrm{Fe}-\mathrm{Al}$ joints, the minimum bonding temperature was near the softening temperatures of copper and iron. In these pairs, the metal transfer of aluminum was observed at $400^{\circ} \mathrm{C}$ on the other metal surface. Therefore, it seems that the oxide film of aluminum is torn by the deformation, but remains on the bonded interface as an inclusion and disturbs the bonding phenomena. According to the observation of the fractured surface in this stage when the true contact area increased, fracture occurred near the bonded interface at the side of the weaker base metal. It seems that the stress concentration occurs in voids because the effect of alloying on the bonding strength is very small as compared with the void size in the bonded interface. Therefore, it is considered that the metallurgical factor has no influence on the bonding strength in this stage.

For this stage, applying Arrhenius' equation to the relation between bonding temperature 
and time, it can be expressed as follows ${ }^{(11)}$ :

$$
1 / t=A_{0} \exp (-Q / R T),
$$

where $Q$ is the activation energy of bonding, $t$ is the duration to constant bonding strength, $A_{0}$ is a constant, $R$ is a gas constant, and $T$ is the bonding temperature. From eq. (1),

$$
\log 1 / t=\log A_{0}-Q / R T \text {. }
$$

Assuming that these joints are a similar bonding condition in the case of the same bonding strength $^{(12)}$ even if the bonding temperature and time are different, let us determine the plotted relation between the reciprocal of various temperature $(1 / T)$ and the time to reach a constant bonding strength $\log (1 / t)(\mathrm{Cu}-\mathrm{Ni}$ $4.5 \mathrm{~kg} / \mathrm{mm}^{2}, \mathrm{Cu}-\mathrm{Ag} 3.1 \mathrm{~kg} / \mathrm{mm}^{2}, \mathrm{Cu}-\mathrm{Al} 2.35$ $\mathrm{kg} / \mathrm{mm}^{2}$, Fe-Al $1.1 \mathrm{~kg} / \mathrm{mm}^{2}$ ). As a result, we obtain a linear relationship for each joint as shown in Fig. 11. From the slope in this plot, the activation energy of bonding required for this process was obtained to be $29400 \mathrm{cal} / \mathrm{mol}$ in $\mathrm{Cu}-\mathrm{Ni}$ joints, $5500 \mathrm{cal} / \mathrm{mol}$ in $\mathrm{Cu}-\mathrm{Ag}$ joints, $20200 \mathrm{cal} / \mathrm{mol}$ in $\mathrm{Cu}-\mathrm{Al}$ joints, and 24000 $\mathrm{cal} / \mathrm{mol}$ in $\mathrm{Fe}-\mathrm{Al}$ joints. On the diffusion bonding, recovery, recrystallization or bulk and
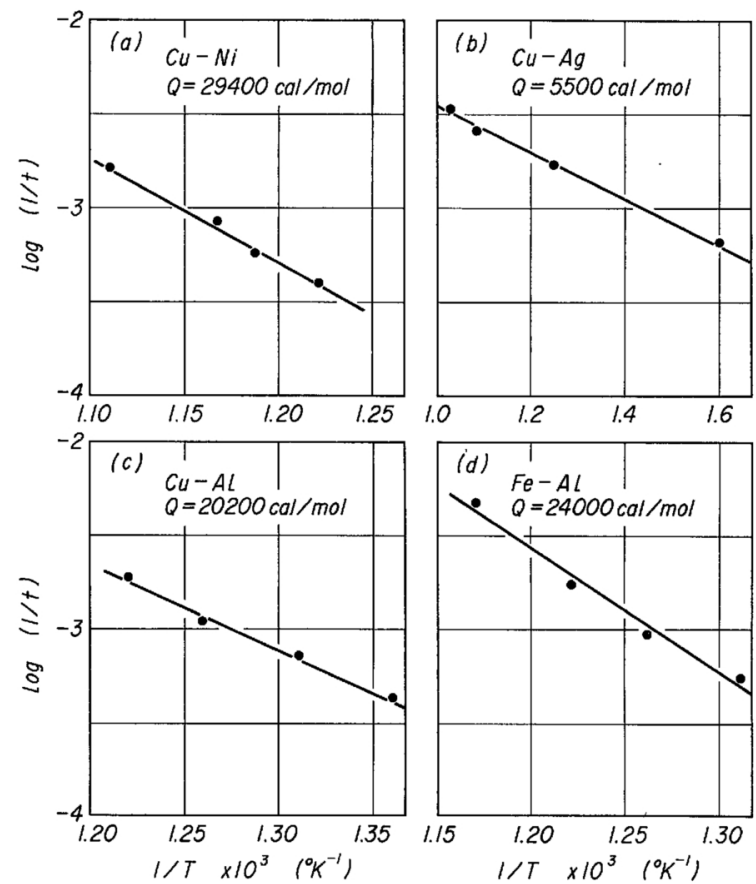

Fig. 11 Relation between $\log (1 / t)$ and bonding temperature for various joints. chemical diffusion are important factors in the acceleration of the bonding process. Hashimoto and Ohashi ${ }^{(12)}$ calculated the activation energies of bonding based on the relation between bonding temperature and bonding time in various reductions and obtained $15 \sim 20 \mathrm{kcal} /$ mol for copper and about $10 \mathrm{kcal} / \mathrm{mol}$ for mild steel. It is not clear which activation energy obtained in this study corresponds to one of the base metals in the each bonding pair. In the case of $\mathrm{Cu}-\mathrm{Al}, \mathrm{Fe}-\mathrm{Al}$, and $\mathrm{Cu}-\mathrm{Ni}$ joints, their activation energies of bonding are larger than the above values but are considerably smaller than the activation energies of bulk diffusion ${ }^{(13)}$ and recrystallization ${ }^{(14)}$ in each metal. It is very complex to make clear the bonding phenomena in terms of activation energies of bonding. This process is considered as a transient phenomenon from recovery to recrystallization with stored energy since the beginning of bonding and the increase of bonding strength occurs near the softening temperature of each metal.

Next, as the second stage in which mutual diffusion is predominant, the processes after recrystallization of both base metals are considered as follows. In this stage where both base metals became soft, voids or other defects do not disappear because the bonding pressure decreases and the vacancy diffusion is restricted $^{(15)}$. So, the increase of the true bonded area is a little. On the other hand, in this stage the mutual diffusion is activated and the effect of alloying on the bonding strength increases. It is considered that each joint shows different weldability on the various combinations of base metals. Figure 12 shows a schematic repre-

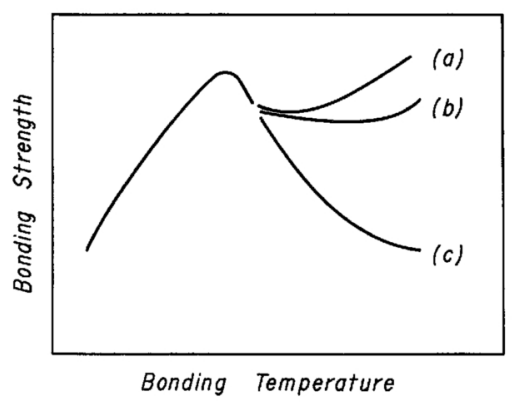

Fig. 12 Schematic representation of the relation between bonding temperature and bonding strength. (a) solid solution type, (b) two-phase type, and (c) intermetallic compound type. 
sentation of the relation between bonding temperature and bonding strength for each type: (a) is the solid solution type, (b) is the two-phase type, and (c) is the intermetallic compound type. In the case of the solid solution type (a), the bonding strength tends to increase gradually with the rise of bonding temperature. It appears that the defects decreases with the rise of bonding temperature near the bonded interface and the mechanical property is improved by the diffusion of nickel on the copper side. As for the two-phase type, the concentration near the bonded interface amounts to the solubility in each metal. After the bonding, the solid solution precipitates with decreasing solubility at the bonded interface. So, the bonded interface becomes a linear incoherent interface and fracture occurs like cleavage fracture and the bonding strength shows a little change. Generally, near the eutectic temperature, a mixed structure of each solid solution exists in the microstructure at the bonded zone and the bonding strength increases rapidly. It has been reported that grain boundary reaction occurs in $\mathrm{Cu}-\mathrm{Ag}$ alloy ${ }^{(16)}$. In the bonding condition where a little change in bonding strength takes place, a copper-rich zone along the silver grain boundary and the bonded interface in microstructure are observed. These phenomena cause a decrease in bonding strength. When fracture occurred in the base metals under such a bonding condition as $700 \sim 775^{\circ} \mathrm{C}$ for $30 \mathrm{~min}$, these structures showed a marked boundary diffusion next to the bonded interface. It seems that these joints increase the bonding strength in the mixed structure of each base metal at the interface. In the case of the intermetallic compound type (c), there was observed $\mathrm{CuAl}_{2}, \mathrm{CuAl}, \mathrm{Cu}_{12} \mathrm{Al}_{9}$, $\mathrm{Cu}_{3} \mathrm{Al}_{2}$ or $\mathrm{FeAl}_{3}$ in the bonded interface. When these compounds form thick layers, the bonding strength deteriorates rapidly because of the brittleness. At the bonding temperature where the formation of the intermetallic compound is slow, the bonding strength tends to increase with time. This tendency is pronounced in $\mathrm{Cu}-\mathrm{Al}$ joints. It is very likely that this is different solubility in the aluminum of copper and iron. In the case of $\mathrm{Cu}-\mathrm{Al}$ joints copper diffuses in aluminum and the mechanical property is strengthened in the bonded interface. In the case of $\mathrm{Fe}-\mathrm{Al}$ joints, however, the very low solubility of aluminum in iron, results in a little change in the mechanical property and a negligibly small effect on the bonding time.

\section{Conclusion}

Metallographical phenomena among many factors which control weldability on diffusion bonding have been investigated. Combinations of the base metals were classified into three types; the solid solution type, two-phase type and intermetallic compound type. The influence of the bonding temperature and time on bonding strength is investigated and the microstructure at the interface is observed.

The results obtained are as follows.

(1) The minimum bonding temperature exists in the neighborhood of the softening temperature of one of the two base metals. Especially, in the solid solution type, the bonding strength increases at the softening temperature of one of the two base metals.

(2) The increasing process of bonding strength at the initial stage is considered as a transient phenomenon from recovery to recrystallization with stored energy and depends on the bonding temperature and time, satisfying Arrhenius' equation.

(3) Bonding strength depends on the softening of base metals and alloying at the interface above the recrystallization temperature of the base metals.

(i) In the case of the solid solution type, the bonding strength increases with the rise of the bonding temperature and time.

(ii) In the case of the two-phase type, the effect of the bonding condition is not so large, but the bonding strength increases rapidly after $30 \mathrm{~min}$ heating at $700^{\circ} \mathrm{C}$.

(iii) In the case of the intermetallic compound type, the alloy layer increases in thickness and the bonding strength rapidly deteriorates in $\mathrm{Fe}-\mathrm{Al}$ joints.

(4) The bonding interface tends to disappear with time above the recrystallization temperatures of both base metals of the solid solution type, but it tends to remain as an interfacial boundary in the case of the two- 
phase and the intermetallic compound type.

\section{Acknowledgments}

The authors would like to thank Mr. Eiji Ito, then a student at Aoyama Gakuin University, for his help in experimental work. Also, they wish to express their thanks to Akashi Gokin Ltd., for supplying specimens, and also to Mr. Yasunobu Tanaka of Shimazu Seisakusho Ltd. for his cooperation in carrying out E.P.M.A. analysis.

\section{REFERENCES}

(1) T. Hashimoto: Bull. Japan Inst. Metals, 13 (1974), 410.

(2) I. Masumoto, K. Tamaki, K. Terai and Y. Nagai: Bull. Japan Inst. Metals, 9 (1970), 653.

(3) N. Yamamoto: Trans. Japan Soc. Mech. Eng., 9-35 (1943), I-98.

(4) E. Rabinowicz: J. Appl. Phys., 32 (1961), 1440.

(5) S. Iwata: Preprints of the 1973 April Meeting of the Japan Inst. Metals, (1973), 179.
(6) T. Hashimoto and O. Ohashi: Preprints of National Meeting of Japan Weld. Soc., 15 (1974), 346.

(7) W. H. King and W. A. Owczarski: Weld. J., 47 (1968), 444s.

(8) Mel M. Schwarts: Modern Metal Joining Techniques, Wiley, (1969), 374.

(9) G. Ito: Corrosion and Engineering, Corona Publishing Co., Ltd., (1969), 33.

(10) Toyota Central R \& D Labs., Inc.: Diagrams and Tables for Quantitative Electron Probe Micro analysis, (1970).

(11) T. Hashimoto and K. Tanuma: J. Japan Weld. Soc., 41 (1972), 19.

(12) T. Hashimoto and O. Ohashi: ibid., 40 (1971), 632.

(13) F. Seitz, D. Turnbull and H. Ehrenreich: Solid State Physics, Academic Press, 22 (1968), 429.

(14) Japan Inst. Metals: Kinzoku-binran, Maruzen, (1971).

(15) H. Ikawa, S. Shin and M. Habu: J. Japan Weld. Soc., 43 (1974), 913.

(16) R. Watanabe: Bull. Japan Inst. Metals, 6 (1967), 436. 